\title{
Midlife Metabolic Profile and the Risk of Late-Life Cognitive Decline
}

\author{
Rosanna Tortelli ${ }^{\mathrm{a}}$, Madia Lozupone ${ }^{\mathrm{b}}$, Vito Guerra ${ }^{\mathrm{c}}$, Maria Rosaria Barulli ${ }^{\mathrm{a}}$, Bruno P. Imbimbo ${ }^{\mathrm{d}}$, \\ Rosa Capozzo $^{\mathrm{a}}$, Alessandra Grasso ${ }^{\mathrm{b}}$, Marianna Tursi ${ }^{\mathrm{b}}$, Cristina Di Dio ${ }^{\mathrm{a}}$, Rodolfo Sardone ${ }^{\mathrm{c}}$, \\ Gianluigi Giannellic ${ }^{\mathrm{c}}$, Davide Seripa ${ }^{\mathrm{e}}$, Giovanni Misciagna ${ }^{\mathrm{c}}$, Francesco Panza ${ }^{\mathrm{a}, \mathrm{b}, \mathrm{e}, *}$ \\ and Giancarlo Logroscino ${ }^{\mathrm{a}, \mathrm{b}, *}$ \\ ${ }^{a}$ Department of Clinical Research in Neurology, Unit of Neurodegenerative Disease, University of Bari "Aldo \\ Moro" at "Pia Fondazione Card. G. Panico", Tricase, Lecce, Italy \\ ${ }^{\mathrm{b}}$ Department of Basic Medicine, Neurodegenerative Disease Unit, Neuroscience, and Sense Organs, \\ University of Bari Aldo Moro, Bari, Italy \\ ${ }^{\mathrm{c}}$ National Institute of Gastroenterology "Saverio de Bellis", Research Hospital, Castellana Grotte Bari, Italy \\ ${ }^{\mathrm{d}}$ Department of Research \& Development, Chiesi Farmaceutici, Parma, Italy \\ ${ }^{\mathrm{e}}$ Department of Medical Sciences, Geriatric Unit and Gerontology-Geriatrics Research Laboratory, \\ IRCCS Casa Sollievo della Sofferenza, San Giovanni Rotondo, Foggia, Italy
}

Accepted 26 April 2017

\begin{abstract}
Among metabolic syndrome components, the effects of higher plasma glucose levels on cognitive decline (CD) have been considered in few studies. We evaluated the associations among midlife glycemia, total cholesterol, high-density lipoprotein cholesterol, triglycerides, midlife insulin resistance [homeostasis model assessment for insulin resistance (HOMAindex)], and CD in the older subjects of the population-based MICOL Study (Castellana Grotte, Italy) at baseline (M1) and at follow-ups seven (M2) and twenty years later (M3). At M1, a dementia risk score and a composite cardiovascular risk score for dementia were calculated. For 797 subjects out of 833, we obtained a Mini-Mental State Examination (MMSE) score at M3, subdividing these subjects in three cognitive functioning subgroups: normal cognition, mild $C D$, and moderate-severe CD. Mean fasting glycemia at baseline was significantly higher in moderate-severe CD subgroup $(114.6 \pm 71.4 \mathrm{mg} / \mathrm{dl})$ than in the normal cognition subgroup (101.2 \pm 20.6$)$. Adjusting for gender, age, and other metabolic components, higher fasting glycemia values both at $\mathrm{M} 1$ [odds ratio $(\mathrm{OR})=1.31 ; 95 \%$ confidence interval $(\mathrm{CI}): 1.08-1.59$ ] and $\mathrm{M} 2(\mathrm{OR}=1.26$; $95 \%$ CI: 1.01-1.57) were associated with an increased risk of moderate-severe CD. Mean HOMA index value was significantly higher in the moderate-severe CD subgroup (5.7 \pm 9.4$)$ compared to the normal cognition subgroup $(2.9 \pm 1.4)$ at M1. The dementia risk probability (MMSE $<24$ ) increased moving through higher categories of the dementia risk score and decreased as long as the cardiovascular score increased. The present findings highlighted the indication to control blood glucose levels, regardless of a diagnosis of diabetes mellitus, as early as midlife for prevention of late-life dementia.
\end{abstract}

Keywords: Alzheimer's disease, cognitive decline, dementia risk scores, diabetes mellitus, fasting glycemia, GreatAGE Study, insulin resistance, metabolic syndrome, nutrition

\footnotetext{
*Correspondence to: Francesco Panza, MD, PhD and Giancarlo Logroscino, MD, PhD, Department of Basic Medicine, Neurodegenerative Disease Unit, Neuroscience, and Sense Organs, University of Bari Aldo Moro, Bari, Italy and Department of Clinical Research in Neurology, University of Bari Aldo Moro, "Pia Fondazione Cardinale G. Panico", Tricase, Lecce, Italy. Tel.: +39 0883 773904; Fax:+390883 773909; E-mails: geriat.dot@uniba.it (Francesco Panza) and giancarlo.logroscino@uniba.it (Giancarlo Logroscino).
}

\section{INTRODUCTION}

As the population gets older, age-related chronic diseases become more prevalent and are of increasing public concern. Furthermore, the influence of obesity and type 2 diabetes mellitus (DM) on brain structure and function has been well established, showing a higher risk of cognitive decline (CD) and dementia $[1,2]$, particularly in older subjects 
[3, 4]. Hence, a potential overlap between brain regions associated with peripheral insulin resistance and Alzheimer's disease (AD) has been proposed [5]. Among the risk factors proposed for sporadic $\mathrm{AD}$, age, family history and the apolipoprotein $\mathrm{E}$ (APOE) $\varepsilon 4$ allele are the only recognized to date [6], However, over the last two decades, the role of metabolic syndrome (MetS) and its components [impaired glucose tolerance, abdominal or central obesity, arterial hypertension, hypertriglyceridemia, and reduced high-density lipoprotein (HDL) cholesterol] has largely emerged in the development of CD and dementia, either from vascular or degenerative origin, so that the definition of "metabolic-cognitive syndrome" (MCS) has been proposed [7].

Several population-based studies suggested that the presence of MetS increased the risk of developing age-related $\mathrm{CD}$, mild cognitive impairment (MCI), AD, and vascular dementia (VaD) [8-11] and the risk of progression from MCI to dementia [11]. Furthermore, individual components of MetS have been linked to the risk of developing CD and dementia. Midlife overweight or obesity [measured by body mass index (BMI)] and midlife central obesity (measured by waist circumference) have been related to an increased risk of CD [12-15], as well as late-life underweight and weight loss $[16,17]$. Epidemiological studies have disclosed an association between DM and increased risk of cognitive impairment and dementia [18, 19]. Additionally, prediabetes and impaired glucose regulation have been found to increase the risk of developing CD [20]. Since dysregulations of blood glucose concentrations have been linked to compromised neurocognitive functions [2], the majority of prediabetes and type $2 \mathrm{DM}$ research has focused on the effects of glycemia and insulin signaling within the brain [21]. Decreases in the sensitivity of central nervous pathways to insulin, i.e., brain insulin resistance (IR), constitute a potential link between metabolic and cognitive dysfunctions [22]. However, there is a lack of population-based studies comparing $\mathrm{CD}$ in older age to metabolic profile described two decades before. The present population-based study aimed to evaluate the association between plasma metabolites (glycemia, total cholesterol, HDL cholesterol, triglycerides) measured in midlife and $\mathrm{CD}$ in late life. Furthermore, in a subgroup of subjects, we studied the association between IR in midlife and $\mathrm{CD}$ in older age. Finally, a dementia risk score and a composite cardiovascular risk score for dementia were calculated at midlife to determine if these risk scores may be predictive of late-life $\mathrm{CD}$ in our population.

\section{MATERIALS AND METHODS}

\section{Study population}

The Multicenter Italian study on Cholelithiasis (MICOL) is a large prospective cohort study on nutrition and risk of cholelitiasis and colon cancer, conducted in the geographic area of Castellana Grotte, Bari, Southern Italy. Methodological details of this population-based study have been published previously [23, 24]. In brief, in 1985, a random sample of 3,500 subjects $(2,000$ men and 1,500 women) aged $\geq 30$ years was drawn from the electoral roll of Castellana Grotte (17,334 residents at the 1981 Census); $30 \%$ worked in the agricultural sector. In 1985-1986, 2,472 (1,429 men and 1,043 women) of 3,500 subjects agreed to take part in the study (70.6\% response rate). A total of 1,028 people did not respond, of these, 127 had changed their address or migrated, 36 had died, and 865 refused to take part to the study. There was no difference in age, sex, or occupation between responders and non-responders. The study was approved by the Institutional Review Board (IRB) of IRCCS "Saverio de Bellis" and informed consent was obtained from each participant before entering the study. The cohort was examined in three surveys: in 1985-1986 MICOL 1 (M1), 1992-1993 MICOL 2 (M2), and 2005-2006 MICOL 3 (M3). This population-based case-control study was conducted in a sub-cohort of 833 subjects that in 2005-2006 were $\geq 65$ years old and whose cognitive status had been evaluated. Subjects of the MICOL cohort enrolled in the present study were now part of a larger population-based study conducted in the same community, the GreatAGE Study. This was a population-based study focused on the impact of nutrition and age-related sensory impairments as predictors of neurodegenerative and psychiatric diseases in older age with high prevalence [25]. At present, we are evaluating subjects 8 years after the Third Survey of the MICOL (M3) Study (sampling frame of registered population on December 31, $2014, N=19,675$, and sample size people $>65$ years, $N=4,205)$.

\section{Measurements}

All subjects at baseline (M1) and at follow-ups (M2 and M3) underwent a venous blood sample 
collection in the morning, after an overnight fast, with measures of fasting glycemia, total cholesterol, HDL cholesterol, and triglycerides. These metabolites were measured within $3 \mathrm{~h}$ hours from the blood sample collection, using standard enzymatic colorimetric methods (Boehringer Mannheim, Germany) under strict quality control. The value of low-density lipoprotein (LDL) cholesterol was derived according the Friedewald formula $(\mathrm{LDL}$ cholesterol $=$ total cholesterol - HDL cholesterol - triglycerides/5) at M1 and M2, and directed measured at M3. Furthermore, anthropometric measures [body weight, height (BMI)] and systolic and diastolic blood pressure (after $10 \mathrm{~min}$ rest), were collected for each subject during baseline and follow-up visits. Patients were also asked to fill in a questionnaire structured in four sections: demographic data, physiological and pathological history, daily diet, and physical activity [26]. In two cohorts of subjects $(n=206$ at M1 and $n=152$ at M2), plasma insulin levels were measured (within $3 \mathrm{~h}$ from the blood sample collection) using a radioimmunoassay kit (Diagnostic Systems Laboratories Inc., Webster, Texas, USA) with an intra-assay coefficient of variation of $6 \%$ and an interassay coefficient of variation of $7 \%$. IR was estimated by using the homeostasis model assessment for IR [HOMA-index: (fasting glu$\operatorname{cose}(\mathrm{mg} / \mathrm{dL}) \times$ fasting insulin $(\mu \mathrm{IU} / \mathrm{ml}) / 405)]$ [27] Global cognitive performance was explored at M3 using the Mini-Mental State Examination (MMSE), that consists of 10 items testing orientation, memory, attention, calculation, language (naming, repeating, auditory comprehension, reading, and writing) and visual-spatial ability, for a maximum total score of 30 [28]. We considered the MMSE score not adjusted that allowed to subgrouping the total sample in three categories: 1) MMSE $>24=$ normal cognition; 2) MMSE between 21 and $24=$ mild CD; and 3) $\mathrm{MMSE}<21=$ moderate/severe CD. We identified diabetic patients at M1, M2, and M3. Diagnosis of DM was made by the presence of one or both of these criteria: 1) diagnosis of DM as revealed in medical records and general practitioner information, and/or 2) use of antidiabetic medications. Finally, al baseline (M1) the Cardiovascular Risk Factors, Aging, and Dementia (CAIDE) Dementia Risk Score (based on age, education, gender, blood pressure, BMI, total cholesterol, and physical activity) [29] and a composite cardiovascular risk score for dementia (based on blood pressure, DM, total cholesterol, and smoking) [30] were calculated.

\section{Statistical analysis}

Mean and standard deviation, for continuous variables and frequency for categorical variables were used in descriptive analysis of all variables studied [age, gender, education level (years), BMI], systolic and diastolic blood pressure, total cholesterol, HDL cholesterol, triglycerides, fasting glycemia, insulin, and IR (HOMA Index). The differences between three categories of not-adjusted MMSE score for single variables examined were evaluated by Analysis of Variance (ANOVA). Subjects with normal cognition were used as control/reference category, and for multiple comparisons the Bonferroni's method for adjusting $p$-values was used. The Multinomial Logistic regression model was performed to determine if different levels of MMSE (normal cognition, mild $\mathrm{CD}$, and moderate/severe $\mathrm{CD})$ were associated with the variables studied, controlling for sex and age, and other covariates such as BMI, total cholesterol, HDL cholesterol, triglycerides, systolic, and diastolic blood pressure. Metabolic profile at baseline was compared in subjects with and without CD twenty years later. Finally, dementia risk probability based on the CAIDE score and a composite vascular score for dementia was calculated using logistic regression model with cognitive status as the dependent variable $(\mathrm{CD}$ of any grade $=$ MMSE score $<24)$, and CAIDE/vascular score risk categories as the independent variable, considering $\beta_{0}$ and $\beta_{1}$ from the logistic regression model, according to the formula Dementia Risk Probability for $\mathrm{n}$ category $=\left[\mathrm{e}^{\left(\mathrm{y}=\left(\beta_{0}+\beta_{1} * \text { Risk Score }\right)\right)} /\left(1+\mathrm{e}^{\left(\mathrm{y}=\left(\beta_{0}+\beta_{1} * \text { Risk Score }\right)\right)}\right)\right]$. When testing the null hypothesis of no association, the probability level of alpha-error, two tails, was set at 0.05 . All the statistical computations were made using STATA 10.0 Statistical Software (StataCorp. 2007. Stata Statistical Software: release 10. College Station, TX: StataCorp LP, USA).

\section{RESULTS}

From 797 subjects out of 833, we obtained a MMSE score at M3. The median unadjusted MMSE score was 29 (range 1-30). Six hundred twenty-seven subjects $(78.7 \%$ ) had a MMSE score $>24$ (normal cognition), 107 (13.4\%) a MMSE score between 21 and 24 (mild CD), and 63 (7.9\%) a MMSE score $<21$ (moderate-severe CD). Demographic and clinical characteristics of the whole cohort and the three cognitive functioning subgroups at M3 are reported 
Table 1

Demographic and clinical characteristics of the whole cohort and the three cognitive functioning subgroups at the Third Survey of the MICOL Study (M3 - 2005-2006)

\begin{tabular}{lcccc}
\hline Parameters $\#$ & $\begin{array}{c}\text { Whole cohort } \\
(n=797)\end{array}$ & $\begin{array}{c}\text { Normal cognition } \\
(n=627)\end{array}$ & $\begin{array}{c}\text { Mild CD } \\
(n=107)\end{array}$ & $\begin{array}{c}\text { Moderate-severe CD } \\
(n=63)\end{array}$ \\
\hline Age (year) & $73.3 \pm 5.6$ & $73.2 \pm 5.7$ & $73.3 \pm 5.0$ & $74.3 \pm 6.2$ \\
Gender (M) (\%) & $418(52.4)$ & $348(55.5)$ & $44(41.1)$ & $26(41.3)$ \\
Education level (years) & $4.9 \pm 3.4$ & $5.2 \pm 3.5$ & $3.9 \pm 3.0$ & $3.5 \pm 3.0$ \\
MMSE & $26.6 \pm 4.0$ & $28.2 \pm 1.7$ & $22.7 \pm 0.8$ & $16.7 \pm 4.4$ \\
\hline
\end{tabular}

\#All values: mean \pm standard deviation. CD, cognitive decline; MMSE, Mini-Mental State Examination; M3, MICOL 3.

Table 2

Metabolic profile and anthropometric characteristics of the whole cohort and the three cognitive functioning subgroups at the three different Surveys of the MICOL Study (M1- 1985-1986, M2 -1992-1993, and M3 -2005-2006)

\begin{tabular}{|c|c|c|c|c|c|c|}
\hline Parameters \# & Cohort & Whole cohort & $\begin{array}{l}\text { Normal cognition } \\
\text { (a) }\end{array}$ & $\begin{array}{l}\text { Mild CD } \\
\text { (b) }\end{array}$ & $\begin{array}{l}\text { Moderate-severe CD } \\
\text { (c) }\end{array}$ & $\mathrm{p}^{\S}$ \\
\hline \multirow[t]{3}{*}{ Diabetes mellitus (yes) (\%) } & M1 & $61(7.6)$ & $47(7.5)$ & $9(8.4)$ & $5(7.9)$ & $0.94^{\circ}$ \\
\hline & M2 & $96(12.7)$ & $71(11.8)$ & $13(13.0)$ & $12(20.7)$ & $0.15^{\circ}$ \\
\hline & M3 & $214(27.0)$ & $165(26.5)$ & $30(28.0)$ & $19(30.2)$ & $0.80^{\circ}$ \\
\hline \multirow{3}{*}{ Body mass index $\left(\mathrm{kg} / \mathrm{m}^{2}\right)$} & M1 & $28.0 \pm 4.3$ & $28.1 \pm 4.3$ & $27.8 \pm 4.6$ & $28.0 \pm 4.0$ & 0.88 \\
\hline & M2 & $28.2 \pm 4.5$ & $28.2 \pm 4.6$ & $28.1 \pm 4.8$ & $28.4 \pm 3.4$ & 0.91 \\
\hline & M3 & $29.8 \pm 5.0$ & $29.9 \pm 5.1$ & $29.6 \pm 5.1$ & $29.3 \pm 4.1$ & 0.66 \\
\hline \multirow[t]{3}{*}{ Systolic blood pressure (mmHg) } & M1 & $134.8 \pm 19.9$ & $134.5 \pm 19.7$ & $135.8 \pm 21.0$ & $135.9 \pm 20.0$ & 0.76 \\
\hline & M2 & $143.0 \pm 21.6$ & $142.8 \pm 21.2$ & $143.6 \pm 21.6$ & $144.5 \pm 25.5$ & 0.81 \\
\hline & M3 & $135.3 \pm 18.7$ & $135.1 \pm 18.6$ & $137.7 \pm 19.2$ & $133.5 \pm 19.1$ & 0.30 \\
\hline \multirow[t]{3}{*}{ Diastolic blood pressure $(\mathrm{mmHg})$} & M1 & $86.4 \pm 11.0$ & $86.4 \pm 11.0$ & $86.4 \pm 10.8$ & $85.8 \pm 11.5$ & 0.91 \\
\hline & M2 & $91.6 \pm 10.3$ & $91.7 \pm 10.4$ & $91.4 \pm 10.2$ & $91.1 \pm 9.1$ & 0.89 \\
\hline & M3 & $74.8 \pm 9.3$ & $75.0 \pm 9.1$ & $91.1 \pm 9.1$ & $73.3 \pm 10.0$ & 0.38 \\
\hline \multirow[t]{3}{*}{ Total cholesterol (mg/dL) } & M1 & $203.3 \pm 42.7$ & $204.3 \pm 41.9$ & $199.9 \pm 49.0$ & $198.7 \pm 39.4$ & 0.42 \\
\hline & M2 & $202.4 \pm 38.8$ & $203.5 \pm 39.4$ & $195.5 \pm 38.8$ & $203.2 \pm 31.3$ & 0.16 \\
\hline & M3 & $192.9 \pm 38.5$ & $192.8 \pm 38.6$ & $193.2 \pm 38.4$ & $193.1 \pm 38.2$ & 0.99 \\
\hline \multirow[t]{3}{*}{ HDL cholesterol (mg/dL) } & M1 & $51.4 \pm 12.9$ & $51.0 \pm 12.6$ & $52.1 \pm 13.4$ & $53.5 \pm 14.7$ & 0.28 \\
\hline & M2 & $50.3 \pm 14.5$ & $49.8 \pm 13.9$ & $51.3 \pm 14.8$ & $52.7 \pm 19.0$ & 0.27 \\
\hline & M3 & $51.4 \pm 13.7$ & $51.1 \pm 13.0$ & $51.8 \pm 15.4$ & $54.4 \pm 17.4$ & 0.19 \\
\hline \multirow[t]{3}{*}{ LDL cholesterol (mg/dL) } & $\mathrm{M} 1^{¥}$ & $123.07 \pm 39.14$ & $124.44 \pm 39.26$ & $117.92 \pm 40.97$ & $118.28 \pm 33.89$ & 0.17 \\
\hline & $\mathrm{M} 2^{¥}$ & $125.39 \pm 37.04$ & $126.64 \pm 37.40$ & $117.21 \pm 37.85$ & $126.44 \pm 30.13$ & 0.06 \\
\hline & M3 & $114.56 \pm 32.57$ & $115.18 \pm 32.63$ & $111.48 \pm 32.17$ & $113.58 \pm 32.82$ & 0.54 \\
\hline \multirow[t]{3}{*}{ Triglycerides (mg/dL) } & M1 & $144.1 \pm 117.0$ & $144.2 \pm 113.7$ & $149.5 \pm 148.7$ & $134.6 \pm 84.4$ & 0.73 \\
\hline & M2 & $133.9 \pm 123.3$ & $135.1 \pm 123.2$ & $134.5 \pm 144.3$ & $120.5 \pm 78.4$ & 0.69 \\
\hline & M3 & $136.3 \pm 101.6$ & $133.8 \pm 86.8$ & $157.4 \pm 172.7$ & $125.0 \pm 66.4$ & 0.05 \\
\hline \multirow[t]{3}{*}{ Fasting glycemia (mg/dL) } & M1 & $102.2 \pm 28.2$ & $101.2 \pm 20.6$ & $100.6 \pm 19.4$ & $114.6 \pm 71.4$ & $0.001^{\wedge}$ \\
\hline & M2 & $103.2 \pm 30.3$ & $102.7 \pm 29.4$ & $102.3 \pm 24.7$ & $110.1 \pm 45.1$ & 0.19 \\
\hline & M3 & $115.5 \pm 33.3$ & $115.5 \pm 33.0$ & $113.3 \pm 31.3$ & $119.7 \pm 39.7$ & 0.48 \\
\hline
\end{tabular}

\#All values: mean \pm standard deviation. CD, cognitive decline; HDL, high-density lipoprotein; LDL, low-density lipoprotein; M1, MICOL 1; M2, MICOL 2; M3, MICOL $3 .{ }^{\S}$ ANOVA (Analysis of Variance); ${ }^{\circ}$ Chi-square test; ${ }^{\wedge}$ Bonferroni comparisons: (a) versus (c) $p=0.0006$, (a) versus (b) $p=1.00 .{ }^{¥}$ LDL cholesterol values calculated with the Friedewald formula: LDL cholesterol = total cholesterol - HDL cholesterol - triglycerides $/ 5$.

in Table 1. Table 2 shows metabolic component values (BMI, systolic and diastolic blood pressure, total cholesterol, HDL cholesterol, LDL cholesterol, triglycerides, and glycemia) and the presence of DM at M1, M2 and M3. ANOVA with Bonferroni correction showed that mean fasting glycemia at baseline (M1) in moderate-severe CD subgroup $(114.6 \pm 71.4 \mathrm{mg} / \mathrm{dl})$, was significantly higher than fasting glycemia in the normal cognition subgroup $(101.2 \pm 20.6 \mathrm{mg} / \mathrm{dl}) \quad(p=0.009) . \quad$ A multinomial logistic regression adjusted for gender, age and metabolic components (BMI, total cholesterol, HDL cholesterol, triglycerides, systolic and diastolic blood pressure) confirmed that higher fasting glycemia values were associated with moderate-severe $\mathrm{CD}$ at M1 [odds ratio $(\mathrm{OR})=1.31 ; 95 \%$ confidence interval (CI): $1.08-1.59 ; p=0.007]$. An increased risk of moderate-severe $\mathrm{CD}$ was found at $\mathrm{M} 2(\mathrm{OR}=1.26$; 95\% CI: $1.01-1.57 ; p=0.04)$. At M3, there was also an increased risk of moderate-severe $\mathrm{CD}$, 
Table 3

Multiple multinomial logistic regression of cognitive functioning subgroups and fasting glycemia at the three different Surveys of the MICOL Study (M1- 1985-1986, M2 -1992-1993, and M3 -2005-2006) corrected for gender, age and metabolic components (body mass index, total cholesterol, high-density lipoprotein cholesterol, triglycerides, systolic and diastolic blood pressure)

\begin{tabular}{|c|c|c|c|c|c|c|c|c|}
\hline & \multicolumn{4}{|c|}{ Mild CD } & \multicolumn{4}{|c|}{ Moderate-severe $\mathrm{CD}^{\#}$} \\
\hline & $\mathrm{OR}$ & $\mathrm{se}(\mathrm{OR})$ & $p$-value & $95 \% \mathrm{CI}$ & OR & $\mathrm{se}(\mathrm{OR})$ & $p$-value & $95 \% \mathrm{CI}$ \\
\hline Fasting glycemia $(\mathrm{mg} / \mathrm{dL})$ at M1 & 1.01 & 0.14 & 0.92 & $0.77-1.33$ & 1.31 & 0.13 & 0.007 & $1.08-1.59$ \\
\hline Fasting glycemia $(\mathrm{mg} / \mathrm{dL})$ at $\mathrm{M} 2$ & 1.03 & 0.12 & 0.78 & $0.82-1.30$ & 1.26 & 0.14 & 0.04 & $1.01-1.57$ \\
\hline Fasting glycemia $(\mathrm{mg} / \mathrm{dL})$ at M3 & 0.90 & 0.11 & 0.39 & $0.71-1.14$ & 1.22 & 0.16 & 0.14 & $0.94-1.59$ \\
\hline
\end{tabular}

\#Reference category: normal cognition subgroup; OR, odds ratio; se, standard error; CI, confidence interval: CD, cognitive decline; OR refers to standard deviation.

Table 4

Dementia risk probability (considering Mini-Mental State Examination score <24) according to different categories of the Cardiovascular Risk Factors, Aging, and Dementia (CAIDE) Dementia Risk Score, and of the composite cardiovascular score at the First Survey of the MICOL Study (Micol 1 - 1985-1986) $(n=797)$

\begin{tabular}{|c|c|c|c|c|c|}
\hline $\begin{array}{l}\text { CAIDE Dementia } \\
\text { Risk Score } \\
\text { categories }\end{array}$ & Demented (n) & $\begin{array}{c}\text { Dementia } \\
\text { Risk } \\
\text { Probability* }\end{array}$ & $\begin{array}{l}\text { Cardiovascular } \\
\text { risk score } \\
\text { categories }\end{array}$ & Demented (n) & $\begin{array}{c}\text { Dementia } \\
\text { Risk } \\
\text { Probability* }\end{array}$ \\
\hline$\overline{0-5}$ & 17 & $19.31 \%$ & 0 & 30 & $26.47 \%$ \\
\hline $6-7$ & 48 & $20.42 \%$ & 1 & 91 & $22.21 \%$ \\
\hline $8-9$ & 60 & $21.58 \%$ & 2 & 43 & $18.45 \%$ \\
\hline $10-11$ & 36 & $22.79 \%$ & 3 & 6 & $15.21 \%$ \\
\hline $12-15$ & 9 & $24.04 \%$ & 4 & 0 & - \\
\hline
\end{tabular}

The CAIDE Dementia Risk Score was based on age ( $<47$ years, 47-53 years, and $>53$ years), education $(>10$ years, $7-9$ years, and $<9$ years), gender, blood pressure (systolic $\geq 140 \mathrm{~mm} \mathrm{Hg}$ ), body mass index $\left(<\right.$ or $>30 \mathrm{Kg} / \mathrm{m}^{2}$ ), total cholesterol $(<$ or $>252 \mathrm{mg} / \mathrm{dL}$ ), and physical activity (yes/no) with a total score $=0-15$ [29]. The composite cardiovascular risk score for dementia was created incorporating presence of: hypertension (systolic $\geq 140 \mathrm{~mm} \mathrm{Hg} /$ diastolic $\geq 90 \mathrm{~mm} \mathrm{Hg}$ ), diabetes (yes), high total cholesterol (total cholesterol $\geq 240 \mathrm{mg} / \mathrm{dL}$ ), and smoking (ever smoked) [30]. *Dementia Risk Probability $=\left[\mathrm{e}^{\mathrm{y}} /\left(1+\mathrm{e}^{\mathrm{y}}\right)\right]$.

but without statistical significance $(\mathrm{OR}=1.22 ; 95 \%$ CI: 0.94-1.59; $p=0.14$ ) (Table 3). Dementia risk probabilities (MMSE score $<24$ ) according to risk categories of the CAIDE Dementia Risk Score and the composite vascular score are reported in Table 4. The dementia risk probability increased moving through higher categories of the CAIDE Dementia Risk Score and decreased as long as the cardiovascular score increased (Table 4). Mean values of plasma insulin levels were $11.6 \pm 4.5 \mu \mathrm{IU} / \mathrm{ml}$ at $\mathrm{M} 1$ and $7.5 \pm 5.8 \mu \mathrm{IU} / \mathrm{ml}$ at $\mathrm{M} 2$ for the normal cognition subgroup. We also calculated the HOMA index at $\mathrm{M} 1(3.1 \pm 3.0)$ and $\mathrm{M} 2(2.1 \pm 2.2)$. Table 5 shows mean plasma insulin levels and mean HOMA indexes at M1 and M2 for the three cognitive functioning subgroups. There was an increasing HOMA index from the normal cognitive cognition to the moderatesevere $\mathrm{CD}$ subgroup both at M1 and M2 that reached significance in the moderate-severe $\mathrm{CD}$ subgroup $(5.7 \pm 9.4)$, compared to the normal cognition subgroup $(2.9 \pm 1.4)$ at $\mathrm{M} 1(p=0.0004)$.

\section{DISCUSSION}

In the present population-based study, we showed an association between higher plasma fasting glucose levels in midlife and moderate-severe $\mathrm{CD}$ in older

Table 5

Plasma insulin levels and homeostasis model assessment for insulin resistance (HOMA-index) in two cohorts by cognitive functioning subgroups (M1- 1985-1986 and M2 -1992-1993).

\begin{tabular}{|c|c|c|c|c|c|c|c|c|}
\hline & \multirow[t]{2}{*}{$\mathrm{N}$} & \multirow[t]{2}{*}{ Parameters \# } & \multirow{2}{*}{$\begin{array}{l}\text { Normal cognition } \\
\text { (a) }\end{array}$} & \multirow{2}{*}{$\begin{array}{l}\text { Mild CD } \\
\text { (b) }\end{array}$} & \multirow{2}{*}{$\begin{array}{l}\text { Moderate-severe CD } \\
\text { (c) }\end{array}$} & \multirow[t]{2}{*}{$\mathrm{p}^{\S}$} & \multicolumn{2}{|c|}{$\mathrm{p}^{\wedge}$} \\
\hline & & & & & & & (a) versus (b) & (a) versus (c) \\
\hline M1 & 206 & Insulin level $(\mu \mathrm{IU} / \mathrm{ml})$ & $11.6 \pm 4.5$ & $11.1 \pm 5.0$ & $13.5 \pm 11.4$ & 0.33 & - & - \\
\hline & & HOMA index ${ }^{¥}$ & $2.9 \pm 1.4$ & $2.8 \pm 1.4$ & $5.7 \pm 9.4$ & 0.0009 & 1.00 & 0.0004 \\
\hline M2 & 152 & Insulin level $(\mu \mathrm{IU} / \mathrm{ml})$ & $7.5 \pm 5.8$ & $7.0 \pm 5.7$ & $11.4 \pm 10.3$ & 0.09 & 1.00 & 0.07 \\
\hline & & HOMA index ${ }^{¥}$ & $2.0 \pm 1.9$ & $1.9 \pm 1.9$ & $3.4 \pm 4.1$ & 0.09 & 1.00 & 0.06 \\
\hline
\end{tabular}

\#All values: mean \pm standard deviation. CD, cognitive decline; M1, MICOL 1; M2, MICOL $2 .{ }^{\S}$ ANOVA (Analysis of Variance). ${ }^{\wedge}$ Bonferroni comparisons. ${ }^{¥}$ HOMA Index $=$ fasting glucose $\times$ fasting insulin $/ 405$. 
age. This association was present in subjects with and without diagnosis of DM and in both sexes. Furthermore, IR measured in midlife in a sub-cohort of older subjects was higher in the group that developed moderate-severe $\mathrm{CD}$ in late life.

According to previous studies, prediabetes and impaired glucose tolerance were shown to increase the risk of developing dementia and AD [20], especially in older women [31]. Nevertheless, the effects of high plasma glucose levels have been considered in few studies with conflicting results. Mortimer and colleagues, in a small Chinese case-control study on older subjects, described high normal fasting blood glucose in individuals with dementia versus amnestic-mild cognitive impairment and normal cognitive status [32]. On the other hand, no association between high fasting plasma glucose levels and dementia was found in a case-control study of 150 Algerian dementia patients compared to 320 older controls with normal cognition [33]. Two independent prospective studies found no association between high baseline fasting glucose levels and cognitive function and/or $\mathrm{CD}$ in individuals without a history of DM after a follow-up period of 5 years [34]. More recently data coming from the National Health and Nutrition Examination Survey showed that among MetS components, high plasma glucose and elevated blood pressure were most strongly associated with $\mathrm{CD}$ [35].

On the other hand, several studies showed an increased risk of developing CD and dementia, both from vascular and degenerative origin in individuals with a history of DM $[20,36]$. In the last fifteen years, the hypothesis that DM could have a role not only in $\mathrm{VaD}$ [37], but also in $\mathrm{AD}$, has emerged. In the 1990s, cross-sectional and longitudinal population-based studies described for the first time a positive association between $\mathrm{DM}$ and $\mathrm{AD}$ [38, 39] and an almost two-fold increase in risk of developing dementia among individuals with DM from different countries [40-42]. Most recently, Wang and colleagues, in a population-based study in Taiwan, described a 50\% increase in risk of developing $\mathrm{AD}$ for individuals with a history of DM, in all sexes and ages, particularly in older diabetic women [43]. Among diabetic individuals, the risk of developing $\mathrm{AD}$ seemed to be higher in the presence of APOE $\varepsilon 4$ allele [44] and uncontrolled DM [45].

Although in the present longitudinal populationbased study, we did not find an association between the diagnosis of $\mathrm{DM}$ and $\mathrm{CD}$, we found a slight, but significant increased risk of late-life $\mathrm{CD}$ in the presence of high fasting plasma glucose levels twenty years before. In the last decade, it has been recognized that midlife, more than late-life vascular and metabolic risk factors, may influence the risk of latelife CD and dementia [46, 47]. For example, several reports have shown that midlife overweight and obesity increased the risk of $\mathrm{CD}, \mathrm{VaD}$, and $\mathrm{AD}$ in late life $[12-15,48,49]$. It is now widely accepted that vascular and metabolic risk factors play an important role in the onset and progression not only of $\mathrm{VaD}$, but also of $\mathrm{AD}$ and other dementias [50,51]. The magnitude of the effect is wider if they are present during midlife, maybe because their biological mechanisms need a long "window period" to determine the pathological process.

In the present study, the effect of fasting plasma glucose level after adjusting for other metabolic risk factors (BMI, total cholesterol, HDL cholesterol, triglycerides, systolic and diastolic blood pressure), suggested that hyperglycemia may be a long-term independent risk factor for future development of $\mathrm{CD}$. The present finding confirmed those from the European Male Ageing Study that found no evidence for a relationship between MetS or inflammation and $\mathrm{CD}$ in a sample of ageing men, while glycemia was negatively associated with visuo-constructional abilities and processing speed in a mean follow-up of 4.4 years [52].

Several biological mechanisms have been proposed to explain the link between altered glucose metabolism and cognitive impairment such as chronic inflammation, microvascular disease, abnormal glycation end products, and chronic peripheral hyperinsulinemia and IR [53-58]. Probably with increasing age, insulin signaling in the peripheral and central nervous system decreases. Individuals with relatively diminished brain insulin sensitivity have a particularly high risk for an AD-like brain pattern, so IR may be a mediator of neurodegeneration [59]. In $A D$, insulin and IR may play a prominent role in amyloid- $\beta(\mathrm{A} \beta)$ metabolism, albeit no coherent pattern has been observed between peripheral IR and amyloid load in the brain, and, conversely, $A \beta$ may affect brain insulin signaling [22, 60]. Insulin regulates $A \beta$ by reducing the phosphorylation of the amyloid- $\beta$ protein precursor, also increasing antiamyloidogenic proteins, such as the insulindegrading enzyme, a metalloprotease that catabolizes insulin. In addition to regulating peripheral insulin levels, insulin-degrading enzyme is highly expressed in the brain and fosters $A \beta$ clearance and intracellular degradation $[22,60]$. 
Altered insulin secretion and function have been also related to $\mathrm{CD}$. A longitudinal study on 2,322 participants, followed up for 32 years reported that impaired insulin response in midlife was associated with an increased risk of AD [61]. Van Oijen and colleagues reported $\mathrm{CD}$ in older women with high levels of fasting insulin secretion in midlife, in comparison to those with lower levels of insulin secretion [62]. Zhong and colleagues showed a negative correlation between MMSE scores and hyperinsulinemia and IR [63], highlighting the role of altered glucose metabolism as a risk factor for CD. Supporting the hypothesis that subclinical alterations of glucose metabolism in middle age may be a risk factor for subsequent $\mathrm{CD}$, in the present study, we found in a subgroup of patients a trend of increment in plasma insulin levels from the normal cognition subgroup to the subgroup with moderate-severe CD and this latter subgroup presented IR at M3 significantly higher than the normal cognition subgroup at M1.

High plasma glucose level in midlife may be related to vascular or mixed dementia and not necessarily to "pure" AD (i.e., without concomitant atherosclerotic cardiovascular disease) [64] or $\mathrm{AD}$ pathology [65]. In our population, we calculated the dementia risk probability according to the different categories of two midlife dementia risk scores (i.e., the CAIDE Dementia Risk Score and a composite cardiovascular score), obtaining conflicting results. In fact, the dementia risk probability increased moving through higher categories of the CAIDE Dementia Risk Score and decreased as long as the cardiovascular score increased. These conflicting results can be related to the characteristics of the present population, in which detailed dementia diagnoses were not available. In fact, we used CD (MMSE score $<24$ ) as a proxy of the clinical diagnosis of dementia. On the other hand, the present conflicting results may underlie that $\mathrm{CD}$ cannot be predicted only by midlife cardiovascular risk factors [30], not taking in account also age, education, gender, and physical activity as in the CAIDE Dementia Risk Score [29].

The major strengths of our study were the longterm follow-up (almost 20 years) on a large cohort of older subjects, the population-based design, and the analysis of plasma metabolites at the time of blood sample collection, avoiding storage and degrading problems. Nevertheless, several limitations should be considered. First, we did not have a diagnosis of dementia syndrome and dementia subtypes made by neurologists, but only a measure of $\mathrm{CD}$ obtained through measure of global cognitive function. Nevertheless, MMSE is the most diffuse and validate screening test to detect cognitive impairment, with a relatively high sensitivity (80-85\%) [66]. Second, we had a single measure of fasting plasma glucose levels only and not repeated longitudinal evaluations to better delineate adult-life metabolic profile and we did not have a complete study of glucose metabolism in these individuals. Also measures of plasma insulin levels and insulin resistance have been performed only in two subgroups of subjects at M1 and M2. Probably, a complete study of the glucose metabolism in middle age and repeated measures to construct metabolic trajectories, associated with a periodic and structured neurologic and neuropsychological assessment, will be helpful to better understand the role of hyperglycemia as a risk factor for $\mathrm{CD}$ and dementia.

In summary, the present findings highlighted the indication to control blood glucose levels, regardless of a diagnosis of DM, as early as midlife for prevention of dementia in late life. These findings may have relevant implications for public health, as the risk of dementia could be reduced identifying "at risk" individuals and controlling glycemia and other vascular factors trough early life-style modifications. It could be worthy to give particular attention in controlling glycemia within the normal range. Dahle and colleagues showed that high-normal blood glucose levels were associated with decreased delayed associative memory, reduced accuracy of working memory processing among women, and slower working memory processing among men, demonstrating that in healthy and not very old adults, normal but elevated values of recognized vascular risk factors were negatively associated with performance in agesensitive cognitive tasks [67]. Blood glucose levels within the normal range are mostly influenced by diet [68], so preventive interventions using low-glycemic index diets may have a large impact on public health.

\section{ACKNOWLEDGMENTS}

Project realized with the financial support of the Apulia Region - Regione Puglia: DGR 751/2014PRIN 2009 DM 14 luglio 2011 n. 404/ric - prot. 2009E4RM.

Authors' disclosures available online (http://j-alz. com/manuscript-disclosures/17-0153r2). 


\section{REFERENCES}

[1] Guh DP, Zhang W, Bansback N, Amarsi Z, Birmingham CL, Anis AH (2009) The incidence of co-morbidities related to obesity and overweight: A systematic review and metaanalysis. BMC Public Health 9, 88.

[2] Koekkoek PS, Kappelle LJ, van den Berg E, Rutten GE, Biessels GJ (2015) Cognitive function in patients with diabetes mellitus: Guidance for daily care. Lancet Neurol 14, 329-340.

[3] Bischof GN, Park DC (2015) Obesity and aging: Consequences for cognition, brain structure, and brain function. Psychosom Med 77, 697-709.

[4] Moheet A, Mangia S, Seaquist ER (2015) Impact of diabetes on cognitive function and brain structure. Ann N Y Acad Sci 1353, 60-71.

[5] Kullmann S, Heni M, Veit R, Ketterer C, Schick F, Häring HU, Fritsche A, Preissl H (2012) The obese brain: Association of body mass index and insulin sensitivity with resting state network functional connectivity. Hum Brain Mapp 33, 1052-1061.

[6] Qiu C, Kivipelto M, Von Strauss E (2009) Epidemiology of Alzheimer's disease: Occurrence, determinants, and strategies toward intervention. Dialogues Clin Neurosci 11, 111-128.

[7] Frisardi V, Solfrizzi V, Capurso C, Imbimbo BP, Vendemiale G, Seripa D, Pilotto A, Panza F (2010) Is insulin resistant brain state a central feature of the metabolic-cognitive syndrome? J Alzheimers Dis 21, 57-63.

[8] Yaffe K, Weston AL, Blackwell T, Krueger K (2009) The metabolic syndrome and development of cognitive impairment among older women. Arch Neurol 66, 324-328.

[9] Razay G, Vreugdenhil A, Wilcock G (2007) The metabolic syndrome and Alzheimer disease. Arch Neurol 64, 93-96.

[10] Solfrizzi V, Scafato E, Capurso C, D'Introno A, Colacicco AM, Frisardi V, Vendemiale G, Baldereschi M, Crepaldi G, Di Carlo A, Galluzzo L, Gandin C, Inzitari D, Maggi S, Capurso A, Panza F; Italian. Longitudinal Study on Ageing Working Group (2010) Metabolic syndrome and the risk of vascular dementia: The Italian Longitudinal Study on Ageing. J Neurol Neurosurg Psychiatry 81, 433-440.

[11] Solfrizzi V, Scafato E, Capurso C, D'Introno A, Colacicco AM, Frisardi V, Vendemiale G, Baldereschi M, Crepaldi G, Di Carlo A, Galluzzo L, Gandin C, Inzitari D, Maggi S, Capurso A, Panza F; for the Italian Longitudinal Study on Aging Working Group (2011) Metabolic syndrome, mild cognitive impairment, and progression to dementia. The Italian Longitudinal Study on Aging. Neurobiol Aging 32, 1932-1941.

[12] Gustafson D, Rothenberg E, Blennow K, Steen B, Skoog I (2003) An 18-year follow-up of overweight and risk of Alzheimer disease. Arch Intern Med 163, 1524-1528.

[13] Kivipelto M, Ngandu T, Fratiglioni L, Viitanen M, Kareholt I, Winblad B, Helkala EL, Tuomilehto J, Soininen H, Nissinen A (2005) Obesity and vascular risk factors at midlife and the risk of dementia and Alzheimer disease. Arch Neurol 62, 1556-1560.

[14] Whitmer RA, Gunderson EP, Barrett-Connor E, QuesenberryJr CP, Yaffe K (2005) Obesity in middle age and future risk of dementia: A 27 year longitudinal population based study. BMJ 330, 1360.

[15] Whitmer RA, Gustafson DR, Barrett-Connor E, Haan MN, Gunderson EP, Yaffe K (2007) Central obesity and increased risk of dementia more than three decades later. Neurology 71, 1057-1064.
[16] Gustafson DR, Bäckman K, Joas E, Waern M, Östling S, Guo X, Skoog I (2012) 37 years of body mass index and dementia: Observations from the prospective population study of women in Gothenburg, Sweden. J Alzheimers Dis 28, 163-171.

[17] Hu G, Horswell R, Wang Y, Li W, Besse J, Xiao K, Chen H, Keller JN, Heymsfield SB, Ryan DH, Katzmarzyk PT (2012) Body mass index and the risk of dementia among Louisiana low income diabetic patients. PLoS One 7, e44537.

[18] Biessels GJ, Staekenborg S, Brunner E, Brayne C, Scheltens $\mathrm{P}$ (2006) Risk of dementia in diabetes mellitus: A systematic review. Lancet Neurol 5, 64-74.

[19] Marseglia A, Fratiglioni L, Laukka EJ, Santoni G, Pedersen NL, Bäckman L, Xu WJ (2016) Early cognitive deficits in type 2 diabetes: A population-based study. J Alzheimers Dis 53, 1069-1078.

[20] Biessels GJ, Strachan MW, Visseren FL, Kappelle LJ, Whitmer RA (2014) Dementia and cognitive decline in type 2 diabetes and prediabetic stages: Towards targeted interventions. Lancet Diabetes Endocrinol 2, 246-255.

[21] Seaquist ER (2015) The impact of diabetes on cerebral structure and function. Psychosom Med 77, 616-621.

[22] Cholerton B, Baker LD, Craft S (2013) Insulin, cognition, dementia. Eur J Pharmacol 719, 170-179.

[23] Misciagna G, Leoci C, Guerra V, Chiloiro M, Elba S, Petruzzi J, Mossa A, Noviello MR, Coviello A, Minutolo MC, Mangini V, Messa C, Cavallini A, De Michele G, Giorgio I (1994) The epidemiology of cholelithiasis in southern Italy. Eur J Gastroenterol Hepatol 6, 937-941.

[24] Osella AR, Misciagna G, Leone A, Di Leo A, Fiore G (1997) Epidemiology of hepatitis $\mathrm{C}$ virus infection in an area of southern Italy. J Hepatol 27, 30-35.

[25] Panza F, Solfrizzi V, Logroscino G (2015) Age-related hearing impairment-a risk factor and frailty marker for dementia and AD. Nat Rev Neurol 11, 166-175.

[26] Willett WC (1997) Nutritional epidemiology, 2nd ed, Oxford University Press, New York.

[27] Matthews DR, Hosker JP, Rudenski AS, Naylor BA, Treacher DF, Turner RC (1985) Homeostasis model assessment: Insulin resistance and beta-cell function from fasting plasma glucose and insulin concentrations in man. Diabetologia 8, 412-419.

[28] Folstein MF, Folstein SE, McHugh PR (1975) "Mini-mental state": A practical method for grading the cognitive state of patients for the clinician. J Psychiatr Res 12, 189-198.

[29] Kivipelto M, Ngandu T, Laatikainen T, Winblad B, Soininen H, Tuomilehto J (2006) Risk score for the prediction of dementia risk in 20 years among middle aged people: A longitudinal, population-based study. Lancet Neurol 5, 735741.

[30] Whitmer RA, Sidney S, Selby J, Johnston SC, Yaffe K (2005) Midlife cardiovascular risk factors and risk of dementia in late life. Neurology 64, 277-281.

[31] Yaffe K, Blackwell T, Kanaya AM, Davidowitz N, BarrettConnor E, Krueger K (2004) Diabetes, impaired fasting glucose, and development of cognitive impairment in older women. Neurology 63, 658-663.

[32] Mortimer JA, Borenstein AR, Ding D, Decarli C, Zhao Q, Copenhaver C, Guo Q, Chu S, Galasko D, Salmon DP, Dai Q, Wu Y, Petersen R, Hong Z (2010) High normal fasting blood glucose is associated with dementia in Chinese elderly. Alzheimers Dement 6, 440-447.

[33] Ramdane S, Daoudi-Gueddah D (2011) Mild hypercholesterolemia, normal plasma triglycerides, and normal glucose 
levels across dementia staging in Alzheimer's disease: A clinical setting-based retrospective study. Am J Alzheimers Dis Other Demen 26, 399-405.

[34] Euser SM, Sattar N, Witteman JC, Bollen EL, Sijbrands EJ, Hofman A, Perry IJ, Breteler MM, Westendorp RG; PROSPER and Rotterdam Study (2010) A prospective analysis of elevated fasting glucose levels and cognitive function in older people: Results from PROSPER and the Rotterdam Study. Diabetes 59, 1601-1607.

[35] Tsai CK, Kao TW, Lee JT, Wu CJ, Hueng DY, Liang CS, Wang GC, Yang FC, Chen WL (2016) Increased risk of cognitive impairment in patients with components of metabolic syndrome. Medicine (Baltimore) 95, e4791.

[36] Logroscino G, Kang JH, Grodstein F (2004) Prospective study of type 2 diabetes and cognitive decline in women aged $70-81$ years. BMJ 328, 548.

[37] Skoog I (1994) Risk factors for vascular dementia: A review. Dementia 5, 137-144.

[38] Ott A, Stolk RP, Hofman A, van Harskamp F, Grobbee DE, Breteler MM (1996) Association of diabetes mellitus and dementia: The Rotterdam Study. Diabetologia 39, 13921327.

[39] Kuusisto J, Koivisto K, Mykkänen L, Helkala EL, Vanhanen M, Hänninen T, Kervinen K, Kesäniemi YA, Riekkinen PJ, Laakso M (1997) Association between features of the insulin resistance syndrome and Alzheimer's disease independently of apolipoprotein E4 phenotype: Cross sectional population based study. BMJ 315, 1045-1049.

[40] Leibson CL, Rocca WA, Hanson VA, Cha R, Kokmen E, O'Brien PC, Palumbo PJ (1997) The risk of dementia among persons with diabetes mellitus: A population-based cohort study. Ann N Y Acad Sci 826, 422-427.

[41] Yoshitake T, Kiyohara Y, Kato I, Ohmura T, Iwamoto H, Nakayama K, Ohmori S, Nomiyama K, Kawano H, Ueda K et al. (1995) Incidence and risk factors of vascular dementia and Alzheimer's disease in a defined elderly Japanese population: The Hisayama Study. Neurology 45, 1161-1168.

[42] Ott A, Stolk RP, van Harskamp F, Pols HA, Hofman A, Breteler MM (1999) Diabetes mellitus and the risk of dementia: The Rotterdam Study. Neurology 53, 1937-1942.

[43] Wang KC, Woung LC, Tsai MT, Liu CC, Su YH, Li CY (2012) Risk of Alzheimer's disease in relation to diabetes: A population-based cohort study. Neuroepidemiology 38, 237-244.

[44] Peila R, Rodriguez BL, Launer LJ (2002) Honolulu-Asia Aging Study, Type 2 diabetes, APOE gene, and the risk for dementia and related pathologies: The Honolulu-Asia Aging Study. Diabetes 51, 1256-1262.

[45] Xu WL, von Strauss E, Qiu CX, Winblad B, Fratiglioni L (2009) Uncontrolled diabetes increases the risk of Alzheimer's disease: A population-based cohort study. Diabetologia 52, 1031-1039.

[46] Kivipelto M, Ngandu T, Fratiglioni L, Viitanen M, Kareholt I, Winblad B, Helkala EL, Tuomilehto J, Soininen H, Nissinen A (2005) Obesity and vascular risk factors at midlife and the risk of dementia and Alzheimer disease. Arch Neurol 62, 1556-1560.

[47] Chiang CJ, Yip PK, Wu SC, Lu CS, Liou CW, Liu HC, Liu CK, Chu CH, Hwang CS, Sung SF, Hsu YD, Chen CC, Liu SI, Yan SH, Fong CS, Chang SF, You SL, Chen CJ (2007) Midlife risk factors for subtypes of dementia: A nested casecontrol study in Taiwan. Am J Geriatr Psychiatry 15, 762 771.

[48] Knopman D, Boland LL, Mosley T, Howard G, Liao D, Szklo M, McGovern P, Folsom AR; Atherosclerosis Risk in
Communities (ARIC) Study Investigators (2001) Cardiovascular risk factors and cognitive decline in middle-aged adults. Neurology 56, 42-48.

[49] Xu WL, Atti AR, Gatz M, Pedersen NL, Johansson B, Fratiglioni L (2011) Midlife overweight and obesity increase late-life dementia risk: A population-based twin study. Neurology 76, 1568-1574.

[50] Silvestrini M, Pasqualetti P, Baruffaldi R, Bartolini M, Handouk Y, Matteis M, Moffa F, Provinciali L, Vernieri F (2006) Cerebrovascular reactivity and cognitive decline in patients with Alzheimer disease. Stroke 37, 1010-1015.

[51] Gorelick PB, Scuteri A, Black SE, Decarli C, Greenberg SM, Iadecola C, Launer LJ, Laurent S, Lopez OL, Nyenhuis D, Petersen RC, Schneider JA, Tzourio C, Arnett DK, Bennett DA, Chui HC, Higashida RT, Lindquist R, Nilsson PM, Roman GC, Sellke FW, Seshadri S; American Heart Association Stroke Council, Council on Epidemiology and Prevention, Council on Cardiovascular Nursing, Council on Cardiovascular Radiology and Intervention, and Council on Cardiovascular Surgery and Anesthesia (2011) Vascular contributions to cognitive impairment and dementia: A statement for healthcare professionals from the American Heart Association/American Stroke Association. Stroke 42, 2672-2713.

[52] Overman MJ, Pendleton N, O’Neill TW, Bartfai G, Casanueva FF, Forti G, Rastrelli G, Giwercman A, Han TS, Huhtaniemi IT, Kula K, Lean ME, Punab M, Lee DM, Correa ES, Ahern T, Laurent MR, Verschueren SM, Antonio L, Gielen E, Rutter MK, Vanderschueren D, Wu FC, Tournoy J, the EMAS study group (2017) Glycaemia but not the metabolic syndrome is associated with cognitive decline: Findings from the European Male Ageing Study. Am J Geriatr Psychiatry 25, 662-671.

[53] Banks WA, Jaspan JB, Kastin AJ (1997) Selective, physiological transport of insulin across the blood-brain barrier: Novel demonstration by species-specific radioimmunoassays. Peptides 18, 1257-1262.

[54] McCrimmon RJ, Ryan CM, Frier BM (2012) Diabetes and cognitive dysfunction. Lancet 379, 2291-2299.

[55] Yaffe K, Lindquist K, Schwartz AV, Vitartas C, Vittinghoff E, Satterfield S, Simonsick EM, Launer L, Rosano C, Cauley JA, Harris T (2011) Advanced glycation end product level, diabetes, and accelerated cognitive aging. Neurology 77, 1351-1356.

[56] Hotamisligil GS (1999) The role of TNF and TNF receptors in obesity and insulin resistance. J Intern Med 245, 621-625.

[57] Jones A, Kulozik P, Ostertag A, Herzig S (2009) Common pathological processes and transcriptional pathways in Alzheimer's disease and type 2 diabetes. $J$ Alzheimers Dis 16, 787-808.

[58] Vekrellis K, Ye Z, Qiu WQ, Walsh D, Hartley D, Chesneau V, Rosner MR, Selkoe DJ (2000) Neurons regulate extracellular levels of amyloid beta-protein via proteolysis by insulin-degrading enzyme. J Neurosci 20, 1657-1665.

[59] Kullmann S, Heni M, Hallschmid M, Fritsche A, Preissl H, Häring HU (2016) Brain insulin resistance at the crossroads of metabolic and cognitive disorders in humans. Physiol Rev 96, 1169-1209.

[60] Verdile G, Fuller SJ, Martins RN (2015) The role of type 2 diabetes in neurodegeneration. Neurobiol Dis $\mathbf{8 4}$, 22-38.

[61] Rönnemaa E, Zethelius B, Sundelöf J, Sundström J, Degerman-Gunnarsson M, Berne C, Lannfelt L, Kilander L (2008) Impaired insulin secretion increases the risk of Alzheimer disease. Neurology 71, 1065-1071. 
[62] van Oijen M, Okereke OI, Kang JH, Pollak MN, Hu FB, Hankinson SE, Grodstein F (2008) Fasting insulin levels and cognitive decline in older women without diabetes. Neuroepidemiology 30, 174-179.

[63] Zhong Y, Miao Y, Jia WP, Yan H, Wang BY, Jin J (2012) Hyperinsulinemia, insulin resistance and cognitive decline in older cohort. Biomed Environ Sci 25, 8-14.

[64] Rantanen K, Strandberg AY, Salomaa V, Pitkälä K, Tilvis RS, Tienari P, Strandberg T (2017) Cardiovascular risk factors and glucose tolerance in midlife and risk of cognitive disorders in old age up to a 49-year follow-up of the Helsinki businessmen study. Ann Med 49, 462-469.

[65] Thambisetty M, Jeffrey Metter E, Yang A, Dolan H, Marano C, Zonderman AB, Troncoso JC, Zhou Y, Wong DF, Ferrucci L, Egan J, Resnick SM, O'Brien RJ (2013) Glucose intolerance, insulin resistance, and pathological features of
Alzheimer disease in the Baltimore Longitudinal Study of Aging. JAMA Neurol 70, 1167-1172.

[66] Tombaugh TN, McIntyre MA (1992) The Mini-Mental State Examination: A comprehensive review. J Am Geriatr Soc 40, 922-935.

[67] Dahle CL, Jacobs BS, Raz N (2009) Aging, vascular risk, and cognition: Blood glucose, pulse pressure, and $\operatorname{cog}$ nitive performance in healthy adults. Psychol Aging 24, 154-162.

[68] Danaei G, Singh GM, Paciorek CJ, Lin JK, Cowan MJ, Finucane MM, Farzadfar F, Stevens GA, Riley LM, Lu Y, Rao M, Ezzati M (2013) Global Burden of Metabolic Risk Factors of Chronic Diseases Collaborating Group, The global cardiovascular risk transition: Associations of four metabolic risk factors with national income, urbanization, and Western diet in 1980 and 2008. Circulation 127, 1493-502, 1502e1-8. 